\title{
BOLAÑO EN GÖTTINGEN
}

\author{
Burkhard Pohl \\ Universidad de Göttingen \\ burkhard-pohl@gmx.de
}

Cuando, a finales del siglo pasado, en el Seminario de Filología Románica empezamos a invitar a escritores latinoamericanos con regularidad, en lo que iba a convertirse en varios años de "Lecturas hispánicas", uno de los primeros nombres fue el de Roberto Bolaño. Gracias al empuje incansable del catedrático Manfred Engelbert, Göttingen era (y es) quizá la universidad alemana que con más ahinco se concentra en la literatura chilena.

Propusimos una conferencia en Göttingen a la editorial Kunstmann, la cual, por su parte, empezó a organizar un ciclo de conferencias alemanas de promoción. Hasta ese momento, solo se había traducido La literatura nazi en América y aparte de su lector, primer traductor y promotor, Heinrich v. Berenberg, parece que en Alemania, como en el resto del mundo, muy pocos habían reparado en la fuerza y originalidad narrativa de Bolaño.

El 24 de mayo de 2000 vino a Göttingen a participar en una presentación de Estrella distante. La sala estaba repleta. Es decir, unos sesenta o setenta jóvenes y no tan jóvenes hispanistas, latinoamericanistas, emigrantes voluntarios o forzados y hasta entusiastas de la literatura dispuestos a conocer a un nuevo escritor que escribiera sobre el drama chileno. Una expectativa, naturalmente, condenada al fracaso.

Todo empezó con poca fortuna. Bolaño llegó sudando, a las ocho menos cinco, acompañado por el delegado de Kunstmann que no parecía haber intimado con él. Llevaba chaqueta gris muy al tono con su expresión grisácea, malhumorada, pero cordial, poco dispuesta a hacer concesiones.

Precisamente, iban a pedirle la primera concesión a pocos minutos de empezar. Por su gran enojo, el novelista se vio obligado a leer un capítulo de su propia obra - una idiosincrasia alemana desconocida en las presentaciones y promociones de libro peninsulares, como se sabe-. Bolaño abrió el libro, eligió un capítulo cualquiera, para leerlo de la formá más monótona y rápida posible, mostrando desgana. Touché.

Después de la pausa, la discusión. Primera pregunta: “¿Qué es para ti un nazi?”. Respuesta bolañiana: "Un nazi es un nazi”. Las caras del público mostraron cierto desconcierto.

Efectivamente, Roberto Bolaño no estaba allí para hablar de política ni para saldar cuentas con la dictadura chilena -más bien, con su literatura-. Y no estaba para hacer 
concesiones al compromiso político como suficiente criterio de valor literario. En cambio, se animó a comentar sobre literatura, sobre Borges, sobre poesía...

Después de la conferencia, fuimos al mejor (y único) restaurante turco de la ciudad, en la Calle Roja. Largas discusiones sobre literatura, duelo a medianoche entre don Manfredo y Bolaño, sobre quién era el mejor escritor chileno, latinoamericano, muerto o viviente.

Ya pasada la medianoche, a conocer la vida nocturna. En el Bar Raro (Sonderbar), antro de los noctámbulos y perdidos por la noche, de los estudiantes eternos de antes de la invención del BA/MA, quedamos cinco en la corte del novelista. Mientras conversábamos bilingües contra el barrullo musical -el cada vez menos entusiasta colaborador editorial, el todavía muy joven futuro novelista argentino Patricio Pron, dos ya no tan jóvenes estudiosos de literatura latinoamericana, un latinoamericano naufragado en la ciudadBolaño se deslizó de la intelectualidad reunida y borracha para hablar en la barra por horas con un muchacho suramericano o caribeño, sobre cualquier cosa, quizá de fútbol.

\section{La siguiente toma:}

A altas horas de la noche, en la Plaza Mayor (es un decir) de Göttingen, parados frente al famoso Gänseliesel, la estatua popular ritualmente besada por académicos laureados. El beso de Roberto Bolaño, sin embargo, se fue a otra parte. Bolaño cruzó la plaza, mostrando de una vez un entusiasmo que había escondido durante gran parte de la noche. Allí estaba la estatuilla de Lichtenberg, Georg Christoph Lichtenberg, que la ciudad había hecho erigir poco antes, recuerdo tardísimo de una herencia cultural heterodoxa. Bolaño tomó a Lichtenberg en sus brazos, lo besó y felicitó a la ciudad, a nosotros y a sí mismo por haber tenido la ocasión de encontrarse con Lichtenberg.

Entre las muchas fotos no tomadas de aquel encuentro en Göttingen me gusta más esta última impresión: Bolaño en bicicleta, dando vueltas vacilantes por la estatua de Lichtenberg.

Al día siguiente, Bolaño tuvo la delicadeza de prestarse a asistir a una reunión con estudiantes de literatura, compartiendo (a veces) y no compartiendo (la mayoría de las veces) opiniones. Provocó a las presentes por su consejo amical -que no se casaran con alguien que se declarara admirador de Isabel Allende-. Consejo que encontró viva resistencia entre el público casi exclusivamente femenino.

De hecho, parece que las discusiones de Göttingen tuvieron su eco en los estudiantes que viajaban a una conferencia sobre Benno von Archimboldi y en las correspondientes diatribas alemanas:

El público, gran parte del cual eran universitarios que habían viajado en tren o en furgonetas desde Gottingen, también optó por las encendidas y lapidarias interpretaciones de Pelletier, sin ningún tipo de reserva, [...] Dos días después, Schwarz y sus adláteres contraatacaron. Contrapusieron a la figura de Archimboldi la de Heinrich Böll. Hablaron de responsabilidad. Contrapusieron a la figura de Archimboldi la de Uwe Johnson. Hablaron de sufrimiento. Contrapusieron a la figura de Archimboldi la de Günter Grass. Hablaron de compromiso cívico. [...] (2666, p. 26). 
Todo esto ocurrió en el año 2000, antes de la eclosión póstuma que tuvo la obra de Roberto Bolaño en Alemania, donde ahora se le está reconociendo como uno de los escritores más importantes de nuestros días.

Algunos meses después, recibí un correo electrónico en el cual me preguntó por la posibilidad de ponerle a uno de sus personajes, un alemán, el nombre de Benno von Archimboldi. Naturalmente, no me atreví a contradecirle.

Solo lo volví a ver una vez: me había invitado a Blanes para charlar de lo que fuera en su casa. Al llegar, sin embargo, el escritor estaba distraído, preocupadísimo por un problema técnico de hardware y pendiente de la llegada del técnico. Hablamos unos diez minutos y me mandó a la playa con su familia y otra amiga de Barcelona. Él se iba a esconder detrás de su escritorio, buscando algún enchufe para un cable y maldiciendo la perfidia del objeto.

Demos, para terminar, la palabra al gran escritor Roberto Bolaño, con unas observaciones futbolísticas perspicaces con motivo de la Eurocopa del 2000, que solo años después se verían contradichas:

Haber visto a Lichtenberg y haber estado con vosotros en Göttingen fue una de las mejores cosas del viaje a Alemania. [...] Por supuesto, las estudiantes de Göttingen constituyen un recuerdo memorable, en especial E., que no sé si es estudiante, profesora o qué. En cualquier caso, una chica muy simpática y políticamente correcta. No creo que España gane la Eurocopa. Mi favorita es Holanda, aunque quién sabe. Dale saludos a Kerstin, Manfred, Pato Pron y sobre todo al gran Georg Cristoph L. Para ti, un fuerte abrazo.

Roberto 